\title{
Nomadic Herded Duck Production as a Livelihood Tool in Some Selected Areas of Bangladesh: A Case Study
}

\author{
S M Rahman, Swapon K Fouzder ${ }^{1}$ and N R Sarker ${ }^{2}$ \\ ${ }^{1}$ Corresponding author: Assistant Professor, Department of Poultry Science, Patuakhali Science and \\ Technology University.E-mail: fouzder@pstu.ac.bd \\ ${ }^{2}$ Principal Scientific Officer, Bangladesh Livestock Research Institute, Savar, Dhaka.
}

\begin{abstract}
Recently popularized nomadic duck production systems in Jamuna Floodplains of Sirajganj and Pabna districts and the lower Padma basin in Faridpur and Madaripur districts of Bangladesh were studied. Direct interviewing and FGD (Focus Group Discussion) was carried out to obtain required data for assessing the profitability of farming, and feeding and management practices in the selected areas. The flock size varied from 146-687 number farm ${ }^{-1}$ depends on the economic base of each farmer. The farmers were categorized into three depending on their number of ducks farm ${ }^{-1}$. Price of each duckling averaged BD Tk. 25.55. Nomads usually moved from place to place for searching natural feeds enriched area from the start of monsoon to mid-autumn. During nomadic rearing, a lump sum amount of supplementary feeds including paddy, wheat and maize grains were supplied in the afternoon after day-long scavenging. The egg production was varied with seasons and availability of natural feeds. Economic analysis revealed that a farmer reared 285 ducks was obtained a gross return of BD Tk. 330450 year $^{-1}$. Non-availability of duck vaccines and insufficient supply of ducklings were the major problems identified in the nomadic duck production system in the areas. It may be concluded that nomadic duck farming is a profitable enterprise and is providing a huge contribution in family income, nutrition and overall livelihood of the farm families in the study.
\end{abstract}

Keywords: Ducks, nomadic system and livelihood

\section{Introduction}

Duck population in Bangladesh comprises about $16.06 \%$ (48.86 million) of the total poultry population (304.17 millions) (Bangladesh Economic Review 2014) and this handsome population is mostly rearing under scavenging and/or free-range systems. Along with other scavenging poultry species ducks play a critical role in meeting daily protein needs and providing household income of farm families in the mixed farming systems of Bangladesh. It is considered to be the women's enterprise because about $80 \%$ female heads of the sampled rearers in rural areas hold the sole responsibility of rearing (Islam et al. 2016). Although a number of potential advantages, duck farming in Bangladesh is decreasing day by day (Islam et al. 2016) which could be due to scarce in scavenging areas and natural feed resources, drying up of natural waterbodies, excessive use of chemicals in crop fields, etc. Transhumant and nomadic duck husbandry is a widely practiced in South and Southeast Asia. The duck flocks often migrate to nearby territory/districts in search of fresh forage and water resources and the only job of the nomads is to forage the ducks and collect the eggs (Tamizhkumaran et al 2013). In Bangladesh, nomadic duck production system has been popularized very recently in Jamuna Floodplains of Sirajgonj and Pabna districts and the lower Padma basin in Faridpur and Madaripur districts. The migration patterns of these nomadic duck rearing depends on the availability of natural waterbodies and feed resources. The present study was directed towards the identification of present status and technological practices followed by the nomadic duck farmers and also to evaluate its impact as livelihood of the rural households.

\section{Materials and Methods}

A purposive survey was carried out in Jamuna Floodplains of Sirajgonj and Pabna districts the lower Padma basin in Faridpur and Madaripur districts among the farmers adopted nomadic duck rearing system using a pre-designed questionnaire. The questionnaire was pre-tested and finalized. Data were collected on rearing practices, especially on farm size, land holdings, feeds and feeding systems, production and production systems, disease incidence, household income and expenditure, etc. Apart from the individual interviewing, FGDs were conducted taking one session in each district to make qualitative analysis. The FGDs were done to find out the impact of nomadic duck rearing on their socioeconomic conditions and to find out effect of duck rearing on livelihood. A total of 38 nomadic farmers were selected. As the number of ducks farm ${ }^{-1}$ affects farmers' income (Huque et al 2001), the farmers in the survey were categorized according to duck herd sizes. The total thirty eight nomads in different districts were divided into three categories having 100-250, 251-500, and above 500 ducks farm ${ }^{-1}$. Data were edited, re-checked, and tabulated after processing. The analysis was done using descriptive statistics like percentage, mean, and rank where appropriate in Microsoft Excel package. 


\section{Farm and family size}

\section{Results and Discussion}

About $52.6 \%$ farmers maintained $\leq 250$ ducks, $36.8 \%$ had $250-500$ and only $10.5 \%$ farmers hold above 500 ducks (Table 1). All the sampled farmers belong to small farm category according to land ownership (BBS 2005, Hossain and Nessa 2005) i.e. their landholdings were between 1.00-2.49 acres. Irrespective of farm size, the overall family size was 5.16. The distribution of ducks according to land size is also shown in Figure 1.

\section{Population dynamics}

Table 2 indicates that cattle and goat heads decreased with the increment of duck population. This could be due to avoid management hazards with higher cattle/goat population which is mostly dominated by the male partners of the family. It means higher duck population simply lowers the availability of family labour for large animals. Results indicate that chicken population household ${ }^{-1}$ increased with increased number of duck farm $^{-1}$. Duck population in different categories of farms averaged 146.50, 369.25 and 687.50, respectively (Table 2).

\section{Source of ducklings and feeding of ducks}

It was observed that most (57-100\%) of the farmers collected day-old ducklings from nearby hatcheries (Table 3). The duck breed in the study area was Khaki Campbell. Results also indicate that large nomads $(>500$ ducks) were not involved in any sort of hatching of his own, although some medium (250-500 ducks) and very few small nomads hatched ducklings. This might be due to that fact that large nomads could not be able to spent extra labour/time for the hatching process. Price of ducklings averaged BD Tk. 25.55 which is almost in agreement with the the findings of Islam et al. (2016). They reported that about $66 \%$ of the sampled farmers purchased each duckling by BD Tk. 24-25. Large farmers spent less time in distant grazing that could be due to availability of natural feed resources in the particular area. However, irrespective of flock size, nomads reared the ducks on 4.62 months of distant grazing, 5.20 months local foraging and 2.19 months confinement feeding in a year. Tamizhkumaran (2013) in a recent study also reported that duration for duck flocks in migratory places ranged from 3-4 months depending upon the rain fall and availability of harvested fields. The availability of natural feeds also varies season to season of the year. Findings indicate that naturals feed resources were abundantly available about four and-a-half months in a year. Natural feeds were scarce on about three and-a-half months. Ducks laid highest number of eggs for a period of about six months usually from September-February (crop harvesting seasons). Due to scarce in natural feed resources ducks' egg laying frequency was poor for a period of about four months (March-April and July-August). Some other researchers (Huque et al 2001, Islam and Sarker 1994a\&b) also found higher egg production during crop harvesting seasons. The duck flocks remaining in the migratory places varied from 2-3 months depending upon the availability of naturals feed resources. Therefore, the year round egg production patterns was variable and which may be due to the availability feeds resources in the waterbodies and on the paddy harvested fields. In addition to foraging, farmers also supplied a little amount of grains such as paddy, whole wheat and maize to the ducks at afternoon adjacent to the night shelter.

All the farmers maintained their ducklings and also their ducks in a traditional manner i.e. night shelter was made temporarily and supplementary feed was at all not on scientific basis. Although traditional, the deficiencies were replenished by the abundant natural feed resources in the major half of the year.

\section{Frequency of disease outbreak}

Most of the farmers reported that duck plague and duck cholera were the major diseases affecting their flocks (Table 4). They also informed that during rice harvesting seasons, poisoning of ducks was observed. Next to these diseases respiratory infection and bird flu were also noticed by the farmers.

Table 5 shows that mortality of ducks was high enough due to outbreak of duck cholera $(48.00 \%)$ which contradict the findings of Tamizhkumaran (2013) who reported ducks plague as major threatening disease. Farmers were aware of the vaccination. But insufficient supply of these vaccines was one of the major constraints. Farmers opined that even after applying duck cholera vaccine, they faced problem with duck cholera. No diseases outbreaks were reported in the flocks of large nomads in the study area. This could be due to planned vaccination and deworming practices.

\section{Contribution in the family income and livelihood of farmers}

Sector wise contributions to total annual family income are presented in Table 6. Duck farming was the dominant sector of family income in all the farm categories and on an average it accounted for about $70 \%$ of the total. Trends indicate that higher farm size (number of ducks) contributed more to the annual family income. The second highest contribution came from field crops. Findings reveal that duck farming was the single largest income source for the livelihood of the farm families in the selected localities. 


\section{Household expenditure}

Household expenditure patterns show that farmers usually maintained some capital as a reserve for restocking of ducklings for the next year (Table 7). Other than operational expenses for brooding, rearing, disease control and supplementary feeds, farmers also invest on an average $36 \%$ of their household income for continuation of duck rearing as a business. Higher expenses in education in the farms having 250-500 ducks may be due to the higher expenses of tuition fees and other costs for their children.

\section{Constraints faced by the farmers}

Problems faced by farmers were ranked from 1-4 based on their perception. Lack of technical knowledge, inadequate supply of quality ducklings and vaccines, disease outbreak, and unavailability of ready feed were the major problems noticed by the respondents. Farmers reared above 500 ducks opined that insufficient reliable workers and unavailability of commercial feed for ducks were the major constraints.

\section{Conclusion and Recommendation}

Since the nomadic duck production is still on a traditional system, location-specific technological interventions are to be carried out to refine the existing practices. Among the diseases, duck plague and duck cholera only causing heavy damage which could be reduced sharply by vaccinating the birds. There are great potentials for an improvement of duck production systems if some constrains could be conquered. The most noticeable constrains are inadequacy in quality ducking and vaccines and lack of technical knowledge in the study area. Regular vaccination and use of balanced supplementary diets may have a great effect on duck production in the localities. This enterprise could provide quality products for human consumption and reducing nutritional deficiencies and poverty reduction. Per annum return from the farm families indicate that nomadic duck farming may be a profitable business.

Government initiatives for organized technological training on duck production practices along with the assurance of availability of quality ducklings and vaccines might have a reflective influence on increased duck population in Bangladesh. If facilities are provided, this enterprise may act as an effective tool for livelihood and food security of the farm families.

\section{References}

[1]. Bangladesh Economic Review. (2014) Ministry of Finance. Government of the People's Republic of Bangladesh, Dhaka. p. 96

[2]. BBS (Bangladesh Bureau of Statistics). (2005) Statistical Pocketbook of Bangladesh. Planning Division, Ministry of Planning, Government of the People's Republic of Bangladesh, Sher-e-Bangla Nagar, Dhaka. p. 150.

[3]. Hossain, S.M.A. \& Nessa, J. (2005) Studies on Livelihood Improvement through Integrated Farming. Final Report submitted to the Research Initiatives Bangladesh, Bangladesh Agril. Univ., Mymensingh, Bangladesh.

[4]. Huque, K.S., Sarker, M.S.K., Huque, Q.M.E. \& Islam, M.N. (2001) Duck production in the Sylhet basin of Bangladesh prospects and problems. Proceeding of the $2^{\text {nd }}$ International poultry show and seminar, February 16-17. pp. 40-51.

[5]. Islam, M.A., Howlider, M.A.R., Alam, M.A., Heyamet, M.A. \& Debnath, M. (2016) Present status, problem and prospect of duck farming in rural areas of Mymensingh district, Bangladesh. Asian J. Med. Biol. Res., 2(2): $202-212$.

[6]. Islam, M. \& Sarker, N.R. (1994a) Study on the performance of local ducks reared under scavenging condition. A report published by Bangladesh Livestock Research Institute (BLRI) on Collaborative Livestock Research and Extension Programme between BLRI and Proshika.

[7]. Islam, M. \& Sarker, N.R. (1994b). Effect of supplementary feeding or growth performance of Khaki Campbell ducklings. A report published by BLRI on Collaborative Livestock Research and Extension Programme between BLRI and Proshika.

[8]. Tamizhkumaran, J., Rao, S.V.N \& Natchimuthu, K. (2013) Nomadic duck rearing in and around Puducherry region - an explorative study. Indian J. Poult. Sci., 48(3): 377-382.

Table 1. Farm and family information

\begin{tabular}{|c|c|c|c|c|}
\hline \multirow[t]{2}{*}{ Parameter } & \multicolumn{3}{|c|}{ Farm size } & \multirow[t]{2}{*}{ All farm } \\
\hline & Up to 250 & $250-500$ & Above 500 & \\
\hline \multicolumn{5}{|c|}{ B. Farm size (Decimal farm $\left.{ }^{-1}\right)$} \\
\hline ii. Pond/ditch & - & 20.21 & - & $7.45(5.40)$ \\
\hline iii. Cultivable land & 103.00 & 140.07 & 87.50 & $115.03(83.35)$ \\
\hline Total & 113.25 & 138.78 & 101.50 & $138.01(100)$ \\
\hline i. Male & 1.45 & 1.93 & 1.50 & $1.63(31.59)$ \\
\hline ii. Female & 1.35 & 1.86 & 1.25 & $1.53(29.65)$ \\
\hline iii. Child & 2.05 & 2.08 & 2.0 & $2.05(39.73)$ \\
\hline Total & 4.85 & 5.71 & 4.75 & $5.16(100)$ \\
\hline
\end{tabular}

Figures in the parenthesis indicate per cent of column total. 
Nomadic herded duck production as a livelihood tool in some selected areas of Bangladesh: A case ..

Table 2. Population dynamics (No. farm ${ }^{-1}$ ) of household livestock and poultry

\begin{tabular}{|c|c|c|c|c|}
\hline \multirow[t]{2}{*}{ Species } & \multicolumn{3}{|c|}{ Farm size } & \multirow[t]{2}{*}{ All farm } \\
\hline & Up to 250 & $250-500$ & Above 500 & \\
\hline Cattle & 2.30 & 3.71 & 1.75 & $2.76(0.91)$ \\
\hline Goat & 1.17 & 0.93 & 0.25 & $1.03(0.34)$ \\
\hline Chicken & 8.65 & 15.86 & 20.75 & $12.58(4.17)$ \\
\hline Duck & 146.50 & 369.25 & 687.50 & $285.53(94.58)$ \\
\hline Total & 158.62 & 389.75 & 710.25 & $301.90(100.00)$ \\
\hline
\end{tabular}

Figures in the parenthesis indicate per cent of column total.

Table 3. Information on ducklings and feeding

\begin{tabular}{|l|c|c|c|c|}
\hline \multirow{2}{*}{ Species } & \multicolumn{3}{|c|}{ Farm size } & \multirow{2}{*}{ All farm } \\
\cline { 2 - 4 } & Up to 250 & $\mathbf{2 5 0 - 5 0 0}$ & Above 500 & \\
\hline i. Source of ducklings & $\begin{array}{l}\text { Local hatchery - 85\% } \\
\text { Distant hatchery -10\% } \\
\text { Own hatchery - 5\% }\end{array}$ & $\begin{array}{l}\text { Local hatchery - 57\% } \\
\text { Distant hatchery -14\% } \\
\text { Own hatchery - 29\% }\end{array}$ & Local hatchery - 100\% & \\
\hline ii. Price of ducklings (Tk) & 25.37 & 25.8 & 25.75 & 25.55 \\
\hline iiii. Grazing (months) & & & & 4.62 \\
\hline Distant grazing & 5.25 & 5.36 & 3.25 & 5.20 \\
\hline Local grazing & 4.80 & 4.29 & 2.5 & 2.19 \\
\hline Confinement & 1.95 & 2.36 & & 4.48 \\
\hline iv. Natural feed avail. (month) & & & 4.50 & 3.93 \\
\hline High & 4.65 & 4.29 & 4.00 & 3.59 \\
\hline Medium & 3.80 & 4.00 & 3.50 & 5.93 \\
\hline Low & 3.55 & 3.71 & & 3.27 \\
\hline v. Laying frequency (month) & & & 5.75 & 2.80 \\
\hline High & 6.10 & 5.93 & 3.75 & 2.50 \\
\hline Medium & 3.00 & 3.07 & & \\
\hline Low & 2.90 & 3.00 & & \\
\hline
\end{tabular}

Table 4. Information on major duck disease outbreak

\begin{tabular}{|l|l|}
\hline Disease/problem & Time of outbreak \\
\hline Duck Cholera & Round the year \\
\hline Duck Plague & Autumn and spring \\
\hline Respiratory problem & Round the year \\
\hline Poisoning & Rice harvesting period \\
\hline Bird flue & Winter $*$ \\
\hline
\end{tabular}

* One farm was affected last year

Table 5. Information of morbidity and mortality of duck (No. farm ${ }^{-1}$ year $^{-1}$ )

\begin{tabular}{|c|c|c|c|c|c|c|}
\hline \multirow[t]{3}{*}{ Disease/problem } & \multicolumn{6}{|c|}{ Farm size } \\
\hline & \multicolumn{2}{|c|}{ Up to 250} & \multicolumn{2}{|c|}{$250-500$} & \multicolumn{2}{|c|}{ Above 500 } \\
\hline & Affected & Dead & Affected & Dead & Affected & Dead \\
\hline Duck Cholera & 18.00 & $8.75(48.61)$ & 28.57 & $13.33(48.66)$ & - & - \\
\hline Duck Plague & 5.00 & $0.25(5.00)$ & 42.86 & $4.93(11.5)$ & - & - \\
\hline Poisoning & 8.00 & $0.95(11.88)$ & 10.71 & $0.71(6.33)$ & - & - \\
\hline Respiratory problem & \multicolumn{6}{|c|}{ A few are affected round the year and some of them die suddenly } \\
\hline Bird flu & - & - & $32.14 *$ & $32.14(100)$ & - & - \\
\hline
\end{tabular}

Figures in the parentheses indicate percent mortality

Table 6. Household income (BD Tk.) farm ${ }^{-1}$ year $^{-1}$

\begin{tabular}{|c|c|c|c|c|}
\hline \multirow{2}{*}{ Sources of income } & \multicolumn{3}{|c|}{ Farm size } & \multirow[t]{2}{*}{ All farm } \\
\hline & Up to 250 & $250-500$ & Above 500 & \\
\hline Crop production & $61750.00(22.30)$ & $74428.57(11.25)$ & $52500.00(6.60)$ & $65447.37(13.83)$ \\
\hline Backyard livestock production & $23900.00(8.63)$ & $40428.57(6.11)$ & $41750.00(5.25)$ & $31868.42(6.73)$ \\
\hline Duck farming & $177892.50(64.24)$ & $449516.07(67.96)$ & $676500.00(85.12)$ & $330449.34(69.85)$ \\
\hline Business & 8500.00 & 89642.86 & 22500.00 & 39868.42 \\
\hline Service & - & 4285.71 & - & 4285.71 \\
\hline Total & 276894.50 & 661373.21 & 794750.00 & 473055.66 \\
\hline
\end{tabular}

Figures in the parentheses indicate percent of total income 
Nomadic herded duck production as a livelihood tool in some selected areas of Bangladesh: A case ..

Table 7. Household expenditure (Tk.) farm ${ }^{-1}$ year $^{-1}$

\begin{tabular}{|l|c|c|c|c|}
\hline \multirow{2}{*}{ Field of expenses } & \multicolumn{3}{|c|}{ Farm size } & \multirow{2}{*}{ All farm } \\
\cline { 2 - 5 } & Up to 250 & $\mathbf{2 5 0 - 5 0 0}$ & Above 500 & 63157.89 \\
\hline Food & 54500.00 & 75000.00 & 65000.00 & 6381.58 \\
\hline Clothing & 4325.00 & 9285.71 & 6500.00 & 7000.00 \\
\hline Health management & 5250.00 & 7428.57 & 14250.00 & 10605.26 \\
\hline Education & 4550.00 & 21428.57 & 3000.00 & 10578.95 \\
\hline Housing & 6650.00 & 13357.14 & 20500.00 & 1986.84 \\
\hline Cosmetics & 1025.00 & 3535.71 & 1375.00 & 124342.11 \\
\hline Land leased & 73750.00 & 167857.14 & 225000.00 & $77763.16(17.08)$ \\
\hline Cost of restocking & $40000.00(14.55)$ & $108571.43(17.73)$ & $158750.00(19.67)$ & $153289.47(36.67)$ \\
\hline Operating capital & $84750.00(30.84)$ & $205714.29(33.60)$ & $312500.00(38.73)$ & $\mathbf{4 5 5 1 0 5 . 2 6}$ \\
\hline Total & $\mathbf{2 7 4 8 0 0 . 0 0}$ & $\mathbf{6 1 2 1 7 8 . 5 7}$ & $\mathbf{8 0 6 8 7 5 . 0 0}$ & $\mathbf{4 5 5}$ \\
\hline
\end{tabular}

Figures in the parentheses indicate percent of total income

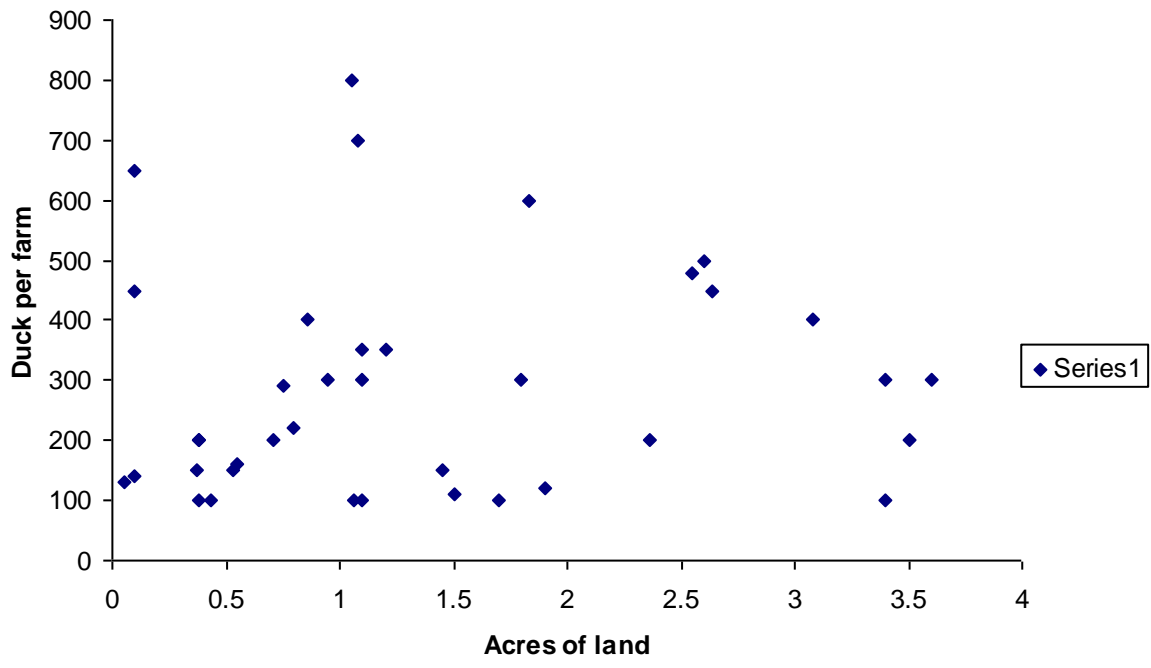

Fig. 1. Number of ducks per farm and the land size of the farms 